\title{
Indeterminação normativa deliberada e liberdades: o melhor interesse da criança entre a coerência e o arbítrio
}

\author{
Deliberate normative indeterminacy and freedoms: the best interest of the child \\ inbetween coherence and arbitrariness
}

André Luiz Arnt Ramos*

\section{Resumo}

As categorias básicas do Direito Civil brasileiro enfrentam mudanças que albergam a promoção de liberdades em diferentes perfis. Este estudo, que segue o método hipotético-dedutivo e o procedimento bibliográfico, parte dessa assunção para construir elementos informadores de decisões em matéria familiar, mormente quando enunciados deliberadamente indeterminados estiverem em jogo, como o melhor interesse da criança, sem olvidar da problemática da controlabilidade frente à indeterminação intencional. Tendo em vista tratar-se de pessoas em formação, demonstra-se que a liberdade substantiva desempenha papel central na definição das funções da família e impõe exigências à tomada de decisões coerentes e estabilizadoras.

Palavras-chave: Coerência normativa. Liberdade substancial. Melhor interesse da criança. Indeterminação normativa deliberada.

\section{Abstract}

The basic categories of Brazilian Civil Law face changes that foster the promotion of freedoms in diverse fields. This study stems from this assumption to assess grounds for decision-making in Family Law, chiefly when indeterminate normative texts - as the best interest of the child - are at stake, while stressing controllability issues derived from intentional indeterminacy. Due to the condition of developing persons, substantive freedom is demonstrated to play a pivotal role in defining the functions of family and the constraints they pose upon coherent and stabilizing decision-making.

Keywords: Normative coherence. Substantive freedom. Best interest of the child. Deliberate normative indeterminacy.

\section{Introdução}

A liberdade, na tradição jurídica brasileira, sofre com grave problema reputacional. ${ }^{1}$ Usualmente (mal) identificada apenas com sua dimensão econômica, parece sempre ser endereçada com desconfiança, como uma espécie de ranço de um tempo que já não é, mas que teima em permanecer - embora, em rigor, jamais tenha sido. ${ }^{2}$ Vertida em termos civis ou existenciais, inspira maior simpatia, mas tende a ser definida em função (e nos rígidos limites) de uma tábua axiológica constitucional - que nem bem é tábua, menos ainda axiológica ${ }^{3}$-, como uma dádiva caprichosa - e graciosamente concedida pelo Estado. Mesmo nessa dimensão, cede diante de verbetes mais consentâneos com a pragmática da coerção, típica dos aparatos

* Doutor e Mestre em Direito das Relações Sociais pela Universidade Federal do Paraná. Professor de Direito Civil da Universidade Positivo. Membro do Grupo de Pesquisa Virada de Copérnico. Associado ao Instituto Brasileiro de Direito Contratual, ao Instituto Brasileiro de Estudos em Responsabilidade Civil e ao Instituto dos Advogados do Paraná. Advogado. Curitiba - PR - Brasil. E-mail: a.arntramos@gmail.com.

Consideração semelhante a respeito da liberdade, seus desafios e possibilidades, no contexto contemporâneo, é formulada por Julie Cohen (2013, passism).

Está-se a fazer referência ao "Estado liberal", arquétipo que mesmo a literatura jurídica refinada enxovalha com certo maniqueísmo, como se fosse o espaço em que a autonomia privada e a propriedade teriam reinado despóticas.

Isto se diz porque "a dimensão prospectiva, umbilicalmente vinculada às suas correspondentes formal e substancial, é constitutiva da própria Constituição, para além do Direito Civil. Esta constatação, cuja consistência imprescinde da aderência a postura hermenêutica tópica e sistemática, põe a desnudo o descompasso da rigidez inata à noção de tábua axiológica com a ordem do dia. É que, se a Constituição se sujeita, ela mesma, a alterações informais (sem observância da rigidez do procedimento para exercício do poder constituinte derivado), não pode encerrar uma tábua de valores. Demais disso e desde o prisma hermenêutico, cujo desenvolvimento escapa às pretensões deste texto, há o dificultoso problema da incontrolabilidade dos valores. Isto muito embora este sintagma tenha sido decisivo para a afirmação, na ágora dos civilistas, da supremacia e da força normativa da Constituição" (ARNT RAMOS, 2018, p. 6). 
estatais. Trata-se, pois e é certo, de um termo sujeito ao problema da carga emotiva da linguagem: em paráfrase da célebre passagem de Alf Ross (1963, p. 267), falar em liberdade é como dar um golpe sobre a mesa.

Não obstante essa problemática, liberdade é, talvez, a grande chave para compreensão do sentido e alcance, não apenas dos institutos fundamentais de Direito Civil, ${ }^{4}$ mas também dos textos normativos de indeterminação deliberada, a exemplo das cláusulas gerais ${ }^{5}$ e das formulações principiológicas. ${ }^{6}$ É dizer: a liberdade, tomada como continente que comporta múltiplos conteúdos, pode, paradoxalmente, amparar os propósitos da segurança jurídica, ${ }^{7}$ a qual, bem compreendida nos esquadros da contemporaneidade, retroalimenta a primeira, em um círculo virtuoso. Para tanto, é necessário despir-se de práticas arraigadas na comunidade jurídica brasileira, de modo a compreender a disciplina das relações entre particulares, sobretudo como ferramental para a persecução das concepções de bem (e de vida boa) de cada pessoa, independentemente de moralidades privadas ou públicas, mundanas ou transcendentais. ${ }^{8}$

Essa possibilidade se revela no trato da proteção integral ou do melhor interesse da criança, princípio que, como sói acontecer com os textos deliberadamente (ou não) indeterminados, serve como uma espécie de licença para a tomada de decisões com base na subjetividade do aplicador do Direito. ${ }^{9}$ Assim - embora não haja explicitação dessa circunstância -, a indeterminação dos textos normativos conferiria margem de discricionariedade ao julgador, que estaria autorizado a decidir conforme sua consciência ${ }^{10}$ ou seu livreconvencimento. Daí, talvez, a inevitável constatação de que, à moda da boa-fé, o melhor interesse da criança seja utilizado como atalho argumentativo, adorno retórico ou varinha de condão pela casuística ${ }^{11}$ do Direito de Família (v. BARBOZA, 2000, p. 210-213).

À vista desses supostos, propõe-se o tracejo de panorama do Direito de Família contemporâneo a partir das diretrizes (Leitlinien) traçadas por Igenborg Schwenzer (2013) no contexto dos debates atinentes à

4 A propósito, diz Pianovski Ruzyk (2011, p. 199): "É daí que pode emergir a função como liberdade(s), a (re)definir um sentido possível da função dos institutos jurídicos do Direito Civil: sendo eles vinculados à intersubjetividade travada entre particulares, podem ser eles instrumentos de exercício e de promoção da(s) liberdade(s), assim compreendidas como possibilidades de auto constituição intersubjetiva - o que pode importar, inclusive, a responsabilidade recíproca entre os indivíduos pela liberdade dos outros".

5 O sentido de cláusula geral é plúrimo, face à vacilância da comunidade jurídica quanto a seu emprego - usa-se o termo de modos sincronicamente diferentes, diacronicamente inconsistentes, singularmente indeterminados e, não raro, mutualmente incompatíveis. Nada obstante, é possível identificar o seguinte sentido operativo: "Cláusula geral é um termo ou sintagma de natureza valorativa caracterizado pela indeterminação, pelo que o significado de tal termo ou sintagma não é determinável (ou, dito de outra maneira, as condições de aplicação do termo ou sintagma não são individualizáveis), senão mediante recurso a critérios potencialmente correntes" (tradução livre. No original: "La clausula generale è un termini o sintagmi di natura valuativa caratterizata da indeterminatezza, per cui il significato di tali termini o sintagmi non è determinabile (o detto altrimenti le condizioni di applicazione del termine o sintagmi non sono individuabili) se non facendo ricorso a critério tra loro potenzialmenti concorrenti" (VELLUZZI, 2010, p. 62-63).

6 Prefere-se o emprego desta expressão à simples menção aos princípios pelo fato de que estes podem constar de enunciados propositadamente "principiológicos", bem como ser extraídos, por indução ou abdução, de outros enunciados normativos. Formulações principiológicas, então, correspondem (i) aos enunciados normativos que escancaradamente se prestam a consagrar princípios e (ii) às proposições formuladas a partir de conjunto(s) de enunciado(s), no curso ou ao termo de processos interpretativos, para efeito de inferência de determinado princípio.

7 Segurança jurídica é significante plurívoco, de cujos sentidos recortam-se: (i) o da tradicional segurança jurídica formal, enraizada no axioma da coincidência entre texto e norma e exprimida na estática da literalidade de textos normativos e relacionada à acepção de caso claro (ou fácil) a partir da clareza da formulação normativa, à moda exegética; e (ii) o da contemporânea segurança jurídica substancial, que pressupõe a clivagem texto-norma, se exprime na dinâmica própria da problemática de casos concretos, bem como em sua resolução dentro dos limites externos da unidade do sistema jurídico; ou seja, a dimensão formal da segurança jurídica corresponde ao que se convencionou referir como direito como segurança, ao passo que sua dimensão material diz com o direito à segurança.

8 Embora com ressalvas quanto ao caráter mais igualitário que liberal de seu pensamento, é disso que fala Dworkin (2011, p. 367 e ss) ao sustentar a independência ética como elemento nuclear às noções siamesas de liberdade e dignidade, inclusive como blindagem da democracia (vertida em sua partnership concepction) a deliberações majoritárias.

9 MacCormick (2006, p. 215) demonstra, a partir de casos emblemáticos julgados pela House of Lords, que esta subjetividade, bastante arraigada na praxe judiciária brasileira (cf. abaixo), não encontra amparo bastante em pretensões de justiça pura e simples, de modo que é limitada, em maior ou menor medida, por exigência de fundamentação coerente e conforme ao Direito. Assim, pode calhar falar em justiça, contanto que seja a justiça conforme o Direito (ou de acordo com a Lei). A propósito: "Os juízes devem, de fato, fazer justiça, mas 'justiça de acordo com a lei'. Isso não significa, na verdade não pode significar, que os juízes devam decidir casos exclusivamente de um modo justificável por simples dedução a partir de normas jurídicas de caráter compulsório. Por outro lado, não pode significar que eles sejam deixados à vontade para seguir suas próprias intuições do senso comum e da utilidade da justiça, livres de todas as limitações. A área de alcance de sua liberdade, poder e, na realidade, deve de buscar soluções justificáveis por meio de uma avaliação em termos consequencialistas das necessidades do caso genérico, é limitada pela exigência de que demonstrem algum fundamento jurídico para o que fazem".

10 A afirmação de que "não me importa o que pensam os doutrinadores. Enquanto for ministro do Superior Tribunal de Justiça, assumo a autoridade da minha jurisdição. [...] Decido, porém, conforme minha consciência", lançada no acórdão que julgou o AgRg no REsp 279.889/AL, publicado no DJe em 11.06.2001, irritou severamente a comunidade jurídica brasileira, especialmente os partidários da chamada Crítica Hermenêutica do Direito, a exemplo de Lênio Streck, que produziu uma espécie de libelo contra esse viés decisionista dos Tribunais no já célebre O que é isto decido conforme minha consciência? - v. STRECK, 2010.

11 A crítica à qual se está a referir provém da pena de Jan Peter Schmidt $(2014$, passim). 
reforma do Código Civil suíço, sem prescindir do estabelecimento dos indispensáveis paralelos com o Direito brasileiro, ${ }^{12} \mathrm{com}$ a inserção do melhor interesse da criança como um enunciado normativo deliberadamente indeterminado, mas irradiador de segurança e promotor de liberdades.

\section{$2 O$ (velho) problema da indeterminação da linguagem jurídica}

A indeterminação da linguagem, particularmente da linguagem jurídica, é um dos problemas centrais das teorias do Direito, especialmente das vertentes conformadoras daquilo que se convencionou chamar de Escola Analítica. ${ }^{13} \mathrm{E}$ nem poderia ser diferente, pois, nas palavras de Aarnio: "[o] Direito é linguagem, e tudo o que se faz na investigação e na prática jurídicas se faz por meio da linguagem". ${ }^{14}$

Mas essa indeterminação que preocupa os analíticos é apenas aquela inerente à linguagem (sobretudo à linguagem ordinária) empregada na formulação das regras - não é demais lembrar que, de modo geral, os positivismos jurídicos vislumbram o Direito como um sistema de regras. ${ }^{1516}$

No contexto jurídico-político dos Estados Constitucionais ${ }^{17}$ - e mesmo fora dele, conquanto constante o perfil contemporâneo ${ }^{18}$-, outras espécies de enunciado normativo de menor densidade, sobretudo as formulações principiológicas, se infiltram na ordem das preocupações dos juristas teóricos e práticos, e findam por recolocar a questão da (in)determinação do Direito. O velho problema, vale dizer, se reformula. ${ }^{19}$ Da zona cinzenta ou de penumbra, avança-se para um intricado jogo de luzes e sombras, a conformar riquíssimo dégradé, por si merecedor de contemplação. E, o que é mais interessante, não raro a imprecisão, o esfumaçamento, dos verbetes empregados na teoria e na prática do Direito é tributária de iniciativa do próprio redator do texto normativo.

Nessa ordem de ideias, as respostas tradicionalmente oferecidas pelos positivismos ao problema da indeterminação (não intencional) da linguagem jurídica (empregada na cunhagem redacional das regras), especificamente as condizentes com a tese da discricionariedade, podem ser veementemente postas em questão. ${ }^{20}$ Esse argumento aponta que o aplicador do Direito, diante de "casos não previstos ou não regulados juridicamente, a um só tempo cria novo Direito, e aplica o Direito vigente, o qual confere e limita seu poder criativo". ${ }^{21}$ Uma ordem jurídica radicada em textos normativos deliberadamente abertos, à moda

12 Não se trata, porém, de uma análise comparada. Almeja-se, apenas, aproveitar a boa sistematização de Schwenzer, que corresponde ceteris paribus ao estado das questões na comunidade jurídica brasileira.

13 Emprega-se a expressão para designar a Analytical Jurisprudence, que finca raízes nas obras de Bentham e Austin e tem, como exponentes ao longo do Século XX, autores da envergadura de Hart e Hohfeld. Para uma abrangente defesa dos pontos de vista compartilhados por esta Escola, v. HART, 1957, passim.

14 Tradução livre. No original: "El Derecho es lenguaje, y todo lo que se hace en la investigación y en la práctica jurídicas se hace por medio del lenguaje" (AARNIO, 2008, p. 8).

15 Outro não é o argumento de Marmor, especificamente quanto aos positivismos do século XX, que "repudiaram este foco na soberania política e o substituíram por uma ênfase nas regras sociais. Em toda sociedade há certas regras sociais que determinam que é o direito, como deve ser identificado, criado e modificado, e essas regras sociais basicamente determinam o que o direito em cada sociedade é." Tradução livre. No original: "Have repudiated this focus on political sovereignty, and replaced it with an emphasis on social rules. In every society there are certain social rules that determine what the law is, how it is to be identified, created and modified, and those social rules basically determine what the law in that society is. An account of the precise nature of these social rules has become rather controversial amongst legal positivists themselves" (MARMOR, 2006, p. 686).

16 É o que aponta Dworkin (1967, p. 22) em sua célebre crítica: "O Positivismo [...] é um modelo de e para um sistema de regras, e sua tese central de apenas um teste fundamental para o direito nos força a perder o importante papel das normativas que não são regras.". Tradução livre. No original: "Positivism [...] is a model of and for a system of rules, and its central notion of a single fundamental test for law forces us to miss the important roles of these standards that are not rules".

17 Para um panorama desta categoria histórica, v. COSTA, 2010, passim.

18 Está-se a referir à tradição anglo-saxã, em cujos esquadros surgiu muito do que hoje se discute, mesmo na europeia continental, acerca da indeterminação da linguagem no Direito, das regras e dos princípios. Isto muito embora a acepção de Constituição inerente a esta seja bastante diversa, inclusive em termos de contexto histórico, daquela. A propósito: DWORKIN, 1967, passim.

19 Em suas feições originais, poderia ser extraído da seguinte afirmação de Aarnio (2008, p. 21): "No contexto jurídico, não obstante, a abertura semântica não se deve a um esforço para alcançar qualidades estéticas. Inclusive, na maioria dos casos, não é intencional”. Tradução livre. No original: "Em el contexto jurídico, no obstante, la apertura semántica no se debe a un esfuerzo por alcanzar cualidades estéticas. Incluso, en la mayoría de los casos, no es intencional".

20 Isto não necessariamente conduz a um rechaço integral e absoluto dos Positivismos jurídicos, como bem sustenta a literatura, inclusive nacional (v. MARANHÃO, 2012, passim).

21 Tradução livre. No original: "legally unprovided-for or unregulated cases the judge both makes new law [with discretion] and applies the established law which both confers and constrains his law-making powers" (HART, 1975, p. 272). 
das democracias constitucionais contemporâneas, é estranha à acolhida da discricionariedade judicial, ${ }^{22}$ mesmo com as ressalvas que Hart (1975) Ihe imprime diante das críticas de Dworkin. Fosse diferente, tais textos normativos não conformariam ordem jurídica democrática, menos ainda constitucional - salvo se brutalmente flexibilizadas as noções de autoria e de sujeito constitucionais, ${ }^{23}$ bem assim se admitida uma acepção de democracia dissociada do princípio majoritário. ${ }^{24}$

Muitas são as respostas oferecidas pelas contemporâneas teorias do Direito; a maior parte delas no bojo daquilo que se tem chamado de pós-positivismo (v. REGLA, 2007). Entre as vertentes mais populares na comunidade jurídica brasileira (ao menos no campo enunciativo), estão a teoria da argumentação jurídica de Robert Alexy (1997, passim) e a teoria do Direito como integridade de Ronald Dworkin (1986, p. 240 e ss.) - abordagens bastante diversas entre si, mas frequentemente confundidas por leituras parcelares e precipitadas -, para além dos tradicionais cânones interpretativos, orientados à resolução de conflitos aparentes de normas.

A meandrosa apropriação que a comunidade jurídica brasileira faz da teoria de Alexy, bem assim seu caráter bastante controvertido (v. BOTERO, 2013), desaconselham a circunscrição do esforço de busca pelos critérios adequados de interpretação e aplicação do Direito contemporâneo em seu pensamento. O mesmo se pode dizer quanto às contribuições de Dworkin, que somente revelam seu potencial numa dada (e bem definida) visão de mundo, quiçá impassível de transposição à realidade socioinstitucional brasileira. Os cânones hermenêuticos tradicionais, malgrado vetustos, decerto não bastam sequer para um primeiro enfrentamento do problema ora recortado, visto que são ferramentas do século XIX próprias para a resolução de problemas típicos do século XIX, de utilidade circunscrita a uma dada acepção de sistema (fechado), de Ciência Jurídica (com "C" maiúsculo), de norma jurídica (texto normativo) e, por consectário, de interpretação.

O ferramental das abordagens referidas ostenta coincidências que permitem delimitar instrumentos adequados a atender aos anseios da Teoria e da Filosofia do Direito, mas também, e sobretudo, da prática jurídica, não raro negligenciada por aquelas ${ }^{25}$ - e a recíproca, claro, é verdadeira. A coincidência está na ênfase que recai sobre o problema da argumentação e do desacordo, seja pela tomada do discurso jurídico como objeto de estudo, seja pela construção de sentidos interpretativos para o Direito (e suas categorias) a partir de desacordos razoáveis. Para além do problema da linguagem, está-se diante do problema da argumentação, marca que se espraia para outros vieses teórico-filosófico-práticos, de incontáveis matizes. Entre eles, destaca-se, para efeito deste trabalho, a Teoria do Direito cunhada a partir das contribuições de Neil MacCormick (2007, passim; AMAYA, 2015, passim), especialmente pelo sentido conferido à noção de

22 É o que crava Amaya (2015, p. 11): “O positivismo jurídico clássico constrói o Direito e o raciocínio jurídico com base em um 'modelo de regras', reduzindo, assim, o raciocínio jurídico à aplicação de regras e à justificação das derivações possíveis desde as regras aplicáveis. Nesta visão, quando regras deixam de oferecer orientação determinada, os juízes têm discricionariedade, pois as razões do Direito alcançam apenas até onde forem as regras. Em contraste, as teorias da coerência vindicam que há limitações ao que os juízes podem fazer nesses casos, nomeadamente limitações de coerência. O Direito não se esvai quando as regras jurídicas não dispõem sobre o caso, pois há razões de coerência pelas quais as decisões jurídicas podem ser justificadas. As teorias da coerência, portanto, visam a alargar o escopo de razoamento no Direito para além dos limites impostos pelo positivismo jurídico clássico". Tradução livre. No original: "Classical legal positivism constructs law and legal reasoning on a 'model of rules', thereby reducing legal reasoning to rule-application and legal justification to derivability from the applicable rules. On this view, when rules fail to provide determinate guidance, judges enjoy discretion, as the reasons of law reach only as far as legal rules do. In contrast, coherence theories claim that there are constraints on what judges may do in these cases, namely, coherence constraints. The law does not run out when legal rules are not dispositive of the case, for there are reasons for coherence by which legal decisions may be justified. Thus, coherence theories aim at enlarging the scope of reason in law beyond the limits imposed by classical legal positivism".

23 O debate acerca desses tópicos é bastante acalentado nos Estados Unidos da América, particularmente em função do célebre início do preâmbulo de sua Constituição: "We the People" (v. MICHELMAN, 1998, p. 64-98).

24 Algumas preocupações próprias do dito constitucionalismo democrático, como a ascendência de uma espécie de juristocracia ou de um Estado Juristocrático, contam com interessante relato em: POKOL, B. The juristocratic State: its victory and possibility of taming. Budapeste: Dialóg Campus Kiadó, 2017, especialmente p. 65 e ss.

25 Manuel Atienza e Juan Ruiz Manero, expoentes latino-americanos da Teoria e da Filosofia do Direito, sinalizam uma espécie de mea culpa na apresentação de importante obra voltada à intersecção entre a jurisprudentia e a Law in Action: "O livro que escrevemos tem essa última circunstância muito em conta, e daí que tenha[mo]s buscado fazer compatível nossa condição de filósofos ou teóricos gerais do Direito com o propósito de nos dirigir a um público amplo de juristas. Dedicamos, por isso, um considerável esforço em conhecer o que os dogmáticos do Direito (sobretudo civilistas e administrativistas) escreveram sobre essas figuras [dos ilícitos atípicos], de modo a confrontar tais escritos com nossas ideias. Por momento, pode parecer inclusive que o nível em que nos situamos é o da dogmática jurídica ou, se se prefere, o que se tem chamado de 'alta dogmática' (dito isso sem a menor pretensão de nossa parte, posto que a altura não significa profundidade, mas apenas nível de abstração). No entanto, nossa análise tem caráter mais reconstrutivo (e menos descritivo) do que se costuma encontrar nos estudos de dogmática jurídica sobre essas matérias" (ATIENZA; MANERO, 2014, p. 14). 
coerência normativa ${ }^{26}$ do discurso jurídico. Vertida em sentido bem mais fraco ${ }^{27}$ que o presente em Dworkin, a coerência de MacCormick exprime, nas palavras de Pugliese, "que as inúmeras normas de um sistema jurídico devem fazer sentido quando consideradas em conjunto" (PUGLIESE, 2016, p. 111).

Vale dizer: em MacCormick, as exigências de coerência, inerentes à justificação jurídica, ${ }^{28}$ remetem à propriedade de um grupo de proposições que, tomadas em conjunto, adquirem sentido como totalidade. Desse modo, a coerência de um agregado de normas é função de sua justificabilidade sob princípios, desde que estes sejam aceitáveis quando tomados em conjunto no delineamento de uma forma de vida satisfatória. ${ }^{29} \mathrm{~A}$ coerência, neste giro, liga-se intimamente a certa concepção de racionalidade, a qual demanda universalidade e generalidade nos princípios práticos. É o que explicita Amaya (2015, p. 85):

As instituições jurídicas estão a serviço de objetivos e a coerência é uma ferramenta valiosa para alcançar alguns deles. Por exemplo, a coerência facilita a coordenação, a efetividade, a segurança jurídica, e a estabilidade social que são, sem dúvida, valores fundamentais nos ordenamentos jurídicos. Por tanto, parece haver razões importantes de ordem prática para promover o valor da coerência no âmbito do direito. ${ }^{30}$

O argumento em prol da coerência remete, via de consequência, à possibilidade de derivação de decisões jurídicas sucessivas a partir do Direito preexistente e do contexto em questão. ${ }^{31}$ Justamente por isso, permite o controle das razões informadoras da tomada de decisões jurídicas pela via analítica (teste da coerência) - (MACCORMICK, 2008, p. 247 e ss.). Assim, pode-se alcançar:

alguma compreensão dos limites do que é considerado legítimo na criação da lei [sic! $]^{32}$ por parte do judiciário. Seria, porém, desvantajoso e enganoso levar por demais a sério noções metafóricas do 'peso', ainda menos do peso relativo, de princípios vistos isoladamente ou em concorrência entre si. É a interação de argumentos a partir de princípios e de argumentos consequencialistas que justifica plenamente as decisões em casos exemplares (MACCORMICK, 2006, p. 254).

A interpretação-aplicação dos textos normativos deliberadamente indeterminados, destarte, não pode prescindir do norte da coerência com o Direito vigente - factível, à vista da homônima, mas contrastante, exigência inerente à tomada do Direito como integridade..$^{33} \mathrm{E}$ mais: as razões determinantes de tal ou qual leitura, além de correlacionadas a cada circunstância concreta, devem ser coesas, consistentes e

26 "A coerência normativa é um mecanismo de justificação, porque pressupõe a ideia de que o Direito é uma empresa racional; porque está de acordo com a noção de universalidade - como componente da racionalidade na vida prática - ao permitir considerar as normas não isoladamente, mas como conjuntos dotados de sentido; porque promove a certeza do Direito, já que as pessoas não podem conhecer com detalhe o ordenamento jurídico -, porém, podem conhecer seus princípios básicos; e porque uma ordem jurídica que fosse simplesmente não contraditória não permitiria orientar a conduta das pessoas, como faz o Direito." (ATIENZA, 2003, p. 129-130).

27 Dworkin formula o que se chama de uma teoria coerentista global determinada do Direito, uma vez que, no Direito como integridade, "as razões de autoridade não têm prioridade com relação às razões morais" (MARANHÃO, 2012, p. 155). V., também: AMAYA, 2009, p. $307-308$.

28 Neste giro, explica Atienza: "A argumentação prática, em geral, e a argumentação jurídica, em particular, cumprem, para MacCormick, essencialmente, uma função de justificação. Essa função justificadora está presente inclusive quando a argumentação persegue uma finalidade de persuasão, pois só se pode persuadir se os argumentos estão justificados, isto é - no caso da argumentação jurídica -, se estão de acordo com os fatos estabelecidos e com as normas vigentes." (ATIENZA, 2003, p. 119).

29 O desenvolvimento desse raciocínio a partir das contribuições de MacCormick não significa adesão irrestrita a seu pensamento. Antes, consiste em emprego de suas categorias e argumentos como ferramental, aliado a contribuições diversas em conteúdo, sentido e origem.

30 Tradução livre. No original: "Las instituciones jurídicas están al servicio de una serie de objetivos y la coherencia es una herramienta valiosa para alcanzar algunos de ellos. Por ejemplo, la coherencia facilita la coordinación, la efectividad, la seguridad jurídica, y la estabilidad social que son, sin duda, valores fundamentales en los ordenamientos jurídicos. Por tanto, parece haber razones importantes de orden práctico para promover el valor de la coherencia en el ámbito del derecho." (AMAYA, 2012, p. 85).

31 A circunscrição do conjunto de coerência ao Direito se deve àquilo que Poscher (2009, p. 103) designa como sua qualidade de Midas: O Direito desenvolve suas próprias concepções de conceitos que compartilha com outras disciplinas, o que seria natural, dadas as diferentes exigências de práticas distintas. Desse modo, "exatamente como tudo em que Midas tocava se tornava ouro, todo conceito incorporado pelo Direito se torna um conceito jurídico, no sentido de que uma concepção específica para o Direito tem que ser adotada”.

32 Evidentemente, o autor está-se a referir ao Direito, não à lei.

33 Está-se a referir ao pensamento de Dworkin (1986, p. 243), para quem: "O Direito como integridade exige que o juiz assuma, tanto quanto possível, que o Direito é estruturado por um conjunto coerente de princípios sobre justiça e equidade e processo legal, e requer que ele os adense nos casos que diante de si surgirem, de modo que a situação de cada pessoa seja justa e equânime segundo aqueles parâmetros. Tal estilo de adjudicação respeita a ambição assumida pela integridade, a ambição de ser uma comunidade de princípio". Tradução livre. No original: "Law as integrity asks judges to assume, so far as this is possible, that the law is structured by a coherent set of principles about justice and fairness and procedural due process, and it asks them to enforce these in the fresh cases that come before them, so that each person's situation is fair and just according to such standards. That style of adjudication respects the ambition integrity assumes, the ambition to be a community of principle". 
universalizáveis. ${ }^{34}$ No âmbito dos institutos fundamentais do Direito Civil, mais especificamente do melhor interesse da criança nas relações familiares, a coerência que se deve guardar - e que costuma ser olvidada por juristas teóricos e práticos - é um princípio multifacetado de liberdade, componente nuclear da dignidade humana e dela indissociável (v. ARNT RAMOS, 2017, passim).

\title{
3 O direito de família contemporâneo: entre a responsabilidade pelo outro e a liberdade
}

O Direito de Família brasileiro pré-Constituição de 1988 era um modelo de tendência monista. Privilegiava-se a família fundada no matrimônio - institucionalizada e formalizada, portanto -, em função da qual critérios legitimadores de pertencimento (e de exclusão) se estabeleciam. A definição de Direito de Família esquadrinhada pela comunidade especializada é disso reveladora e sua leitura basta por si só:

\begin{abstract}
Dentre as conceituações propostas na doutrina, duas, ao menos, se impõem por suas características e pela precisão. A primeira, sintética, expressa que o Direito de Família 'é o conjunto de regras aplicáveis às relações entre pessoas ligadas pelo casamento ou parentesco'. Reveste-se a outra de índole analítica: 'complexo de princípios que regulam a celebração do casamento, sua validade e os efeitos que dele resultam, as relações pessoais e econômicas da sociedade conjugal, a dissolução desta, as relações entre pais e filhos, o vínculo do parentesco e os institutos complementares da tutela, curatela e ausência'.
\end{abstract}

Ao tempo em que proposta a segunda definição, ainda não existia, no direito positivo, o instituto do divórcio, que sobreveio apenas em 1977. Assim, sai versão hodierna incluiria também a desconstituição do matrimônio a este título (ALMADA, 1987, p. 20).

Esse viés exclusivista (e excludente), centrado na família legítima, delineada pelo matrimônio, e na consequente desqualificação das relações extramatrimoniais, especialmente de filiação, cedeu. Cedeu em prol do vislumbre de uma intransigente abertura constitucional à pluralidade de relações familiares, informadas sobretudo pelo afeto. ${ }^{35} \mathrm{Cedeu}$, também, à vista de um compromisso basal com a igualdade: de gênero, de orientação sexual e de origem na filiação (v. BODIN DE MORAES, 2013), ao que se acresce a igualdade de crédito de proteção entre as diversas entidades familiares (LÔBO, 2002) existentes de fato. ${ }^{36}$

A família do Direito Civil brasileiro contemporâneo não é mais apenas a legítima e matrimonial; não é mais continente de um organograma encabeçado por figura soturna. É, antes, um espaço amorfo de afeto e solidariedade, inspirado pela promoção do desenvolvimento das potencialidades de seus integrantes. ${ }^{37}$ Nesse quadro, a família transcende suas funções institucionais "para retratar também os projetos pessoais de cada um de seus membros, na busca pela sua realização e felicidade, sem perder de vista, contudo, a mesma projeção para o todo familiar" (HIRONAKA, 2013, p. 30). No dizer de Ana Carla Matos (2913, p. 320), "são os fios do afeto que tecem a roupagem da família contemporânea, agasalhando a pessoa e sua dignidade à luz dos valores consagrados na Constituição da República”. Daí se afirmar, com Fachin (2015, p. 161):

34 Esta qualidade é central no pensamento de MacCormick (2008, p. 131), pois, em suas palavras: "Não há nenhuma justificação sem universalização; a motivação não precisa de universalização; e a explicação requer generalização. Para que fatos particulares possam ser razões justificadoras, eles têm de ser subsumíveis a um princípio relevante de ação universalmente afirmado, mesmo que a proposição universal respectiva seja reconhecidamente excepcionável".

35 O parecer de Pianovski Ruzyk (2011, p. 325) é bastante eloquente neste sentido: "Trata-se da passagem da concepção institucionalista de família, cuja dimensão funcional conduzia à conformação de modelos autoritários e centrados na estabilidade do ente familiar para uma família em que prevalecem as aspirações coexistenciais, tendo como leitmotiv o afeto".

36 A propósito: "Nesse andamento, importa destacar que se a família for pensada em um viés plural e aberto, apreendida como espaço de uma autoconstituição coexistencial, não caberia nem ao Estado nem à comunidade a definição exclusiva de como essa autoconstituição será desenvolvida, em quais pilares essa autoconstituição se sustentará ou quais cores passará ela a exprimir. [...] Pretender, assim, projetar uma espécie de arrimo a tal painel de possibilidades, no âmbito dessas perspectivas, traduz o sinônimo de respeitar e acatar escolhas pessoais. [...] Todas as uniões são fontes de relações das famílias" (FACHIN, 2015, p. 163-164).

37 Acerca do tema, enuncia Fachin (2015): "Progressivamente, com o surgimento do desenho de afeto no plano dos fatos, ela [a família] se inscreve numa trajetória de direitos subjetivos: de espaço de poder se abre para o terreno da liberdade: o direito de ser ou de estar, e como se quer ser ou estar". 
Eis que o tradicional modelo familiar, que instrumentalizava as relações sociais como instituição erigida sobre o tríplice estandarte do matrimônio, do patrimônio e do pátrio poder, dá lugar à família nuclear eudemonista, cujo feixe luminoso passa a focar-se por sobre as pessoas que nela se encontram afetivamente envolvidas.

\section{$[\ldots]$}

Naquele passo, a família era limitada a representar uma aquarela de tonalidades e cores morais e sociais, em lugar de ser uma tela policrômica para o desenho do sentimento e do afeto.

Essa renovada estruturação familiar abriu as portas à compreensão e ao reconhecimento de inúmeros outros tons, a rigor sem modelos excludentes, resultado de uma série de transformações sociais, especialmente ocorridas aos anos que sucederam a gênese da nova ordem constitucional. ${ }^{38}$

Essa viragem no governo jurídico das relações familiares, quiçá a única que se credencie à alcunha de paradigmática, desafia a pungência da provocação de Timsit (1996, p. 83), de que codificar não é modificar, ${ }^{39}$ anunciada expressamente por Reale ${ }^{40}$ relativamente ao Código Civil brasileiro. E teve, como principal vetor de mudança, a alteração do eixo de importância no governo jurídico das relações familiares: da estrutura da(s) entidade(s) familiar(es) para a pessoa dos filhos e seu pleno desenvolvimento, atendido seu (absolutamente prioritário) melhor interesse.

Nesse prisma, a autoridade dos pais sobre os filhos recebe nova significação: antes de um direito dos pais, é deles um dever. Um dever de promover o melhor interesse daqueles, mesmo (e sobretudo) em circunstâncias conflituosas, próprias da extinção de relações afetivas entre os adultos, as quais, por seu turno, são caras à afirmação da dita família democrática. Exatamente as mesmas diretrizes são traçadas por Ingeborg Schwenzer no contexto de debates acerca da atualização do Código Civil suíço.

Segundo a professora da Universidade da Basileia, quatro seriam as diretrizes fundamentais de um Direito de Família contemporâneo: (i) o desvalor de normativas protetoras de instituições familiares (Kein Eheinstitutionenschutz), pois "as normas de Direito de Família hoje não mais podem se apegar ao status, mas devem, antes, ser adequadas à construção da pluralidade das relações familiares" (SCHWENZER, 2013); (ii) o princípio da não intervenção (Prinzip der Nichteinmischung), ou da intervenção mínima do Estado e de seu Direito, sobretudo no que tange à acomodação dos interesses dos adultos; ${ }^{41}$ (iii) o bem-estar da criança (Kindeswohl), com tal intensidade que "não restam dúvidas de que a primazia suprema de todo Direito de Família deva recair sobre o bem-estar da criança", ${ }^{42}$ o qual se afirma soberanamente frente aos interesses dos adultos; e (iv) uma reivindicação de responsabilidade (Einfordern von Verantwortung), a qual delimita o alcance das responsabilidades da família e do Estado em matéria familiar, bem assim confere sentido à frequentemente invocada solidariedade (SCHWENZER, 2013, p. 10). Aqui - é curioso notar - está-se a enfatizar a responsabilidade prospectiva pelo outro, mas no sentido de dever promocional, em detrimento da responsabilidade como resposta (ainda que antecedente) a determinado dano ou fato antijurídico, o que se denota já pelos verbetes empregados por Schwenzer: fala-se em Verantwortung (responsabilidade), não em Haftung (responsabilidade civil ou por danos). Isto corresponde, quantum satis, à leitura da contemporânea responsabilidade no Direito de Família esposada por Paulo Lôbo (2011, p. 51), que diz:

\footnotetext{
8 Este diagnóstico é reforçado em Bodin de Moraes (2013, p. 592-593), para quem: "[E]m contraposição ao modelo familiar tradicional [...], tornouse possível propor uma configuração democrática de família, na qual não há direitos sem responsabilidades, nem autoridade sem democracia. [...] O adjetivo 'democrático' diz respeito à rejeição de qualquer discriminação e preconceito, à liberdade de decidir o curso da própria vida e ao direito de protagonizar igual papel ao forjar um destino comum. [...] Famílias democratizadas nada mais são do que famílias em que a dignidade de cada membro é respeitada e tutelada. Para a concretização desse processo, o que mais cumpre ressaltar é a sua pluralidade: o fenômeno familiar não é mais unitário".

39 Tradução livre. No original: "Codifier n'est pás modifier".

40 Está-se a referir ao compromisso da comissão de juristas envolvida no projeto que viria a se tornar o Código Civil de 2002 em "não dar guarida no Código senão aos institutos e soluções normativas já dotados de certa sedimentação e estabilidade” (REALE, 1986, p. 76).

41 Diz a autora: "Interesses públicos hoje não mais podem justificar as regras de coexistência humana, relativamente a pessoas adultas que são capazes de regular seus assuntos pessoais e de resolver problemas, mesmo de acordo com o bem-estar da criança.". Tradução livre. No original: "Öffentliche Interessen können heutzutage Regelungen des menschlichen Zusammenlebens nicht mehr rechtfertigen, wo immer erwachsene Menschen in der Lage sind, ihre persönlichen Angelegenheiten selbst zu regeln und Probleme auch unter Beachtung des Kindeswohls zu lösen." (SCHWENZER, 2014, p. 9).

42 Tradução livre. No original: "Es kann kein Zweifel bestehen, dass oberster Primat eines jeden Familienrechts das Kindeswohl sein muss" (SCHWENZER, 2013, p. 10).
} 
A responsabilidade na família é pluridimensional e não se esgota nas consequências dos atos do passado [...]. Mais importante e desafiadora é a responsabilidade pela promoção dos outros integrantes das relações familiares [...]. A família, mais que qualquer outro organismo social, carrega consigo o compromisso com o futuro.

Para além dessa conexão de sentido entre a responsabilidade na família e a Verantwortung enaltecida por Schwenzer, há correspondências entre as demais diretrizes por esta traçadas e o diagnóstico que se faz das normativas fundantes do hodierno Direito de Família brasileiro. Assim, o desprestígio do status em prol dos relacionamentos afetivos guarda paralelo com os princípios da pluralidade e da igualdade das entidades familiares (v. LÔBO, 2002); a não intervenção dialoga com a valoração positiva da liberdade, sobretudo dos adultos (v. BODIN DE MORAES, 2013, p. 613 e ss.; PIANOVSKI RUZYK, 2005, passim), e da configuração eudemonista da família, ${ }^{43}$ a promoção da responsabilidade tem com a afirmação da paternidade responsável; ${ }^{44} \mathrm{e}$ o prestígio ao bem-estar da criança tem correspondência à tutela de seu melhor interesse..$^{45} \mathrm{E}$ o motor dessas transformações normativas, as mudanças sociodemográficas que acusam a força jurígena dos fatos, ${ }^{46}$ é, também, coincidente (v. SCHWENZER; AESCHLIMANN, 2006; CARBONERA, 2013).

Essas viragens e renovadas normativas fundamentais, são, pelo perfil das famílias sob a égide constitucional, norteadas pelo melhor interesse da criança e enfeixadas pela responsabilidade (Verantwortung) familiar. A questão fundamental (carente, ainda, de resposta adequada na comunidade jurídica brasileira) é, pois, precisar qual o sentido das vindicações inerentes à promoção do melhor interesse da criança (ou de seu bem-estar). Isto é: saber qual a ratio que, diante de circunstâncias concretas, deve presidir a invocação desse texto normativo deliberadamente indeterminado, de modo a atender à exigência de coerência em sua aplicação. E assim é porque ao jurídico compete "oferecer instrumentos para que o exercício da liberdade não seja a aniquilação da liberdade e da dignidade do outro" (PIANOVSKI RUZYK, 2011, p. 327).

Nessa ordem de ideias, em que confluem plúrimos perfis de liberdade, é particularmente sensível, justamente pelo fato de se estar a tratar de seres em desenvolvimento, a temática da liberdade substanciale do capabilities approach (v. NUSSBAUM, 2007, p. 82-84) consagrado por Anartya Sen e Martha Nussbaum. Isto não significa obnubilar as dimensões negativa ${ }^{47}$ e positiva ${ }^{48}$ da liberdade, mesmo porque não prescindem de conjuntos capacitatórios elementares à conformação e à persecução de concepções autônomas de bem.

43 "É a afeição ínsita na família. O amor entre pais e filhos, se refere aos cuidados que um tem para com o outro. Portanto, família é aquela fundada no amor que traduz esta atenção especial entre pais e filhos. Este é o verdadeiro sentido da família eudemonista. Família base da sociedade, lócus privilegiado de realização de todos os seus membros, independentemente do modelo familiar escolhido. Relações de afeto lastradas nos princípios da dignidade da pessoa humana e da solidariedade." (ALBUQUERQUE, 2012, p. 87).

44 Trata-se de uma profunda ressignificação do pátrio poder, no sentido de nele vislumbrar função promotora da liberdade e da dignidade dos integrantes de determinada comunidade de afeto. A propósito: "A função delineada pela ordem jurídica para a autoridade parental, que justifica o espectro de poderes conferidos aos pais - muitas vezes em detrimento da isonomia na relação com os filhos, e em sacrifício da privacidade e das liberdades individuais dos filhos - só merece tutela se exercida como um múnus privado, um complexo de direitos e deveres visando ao melhor interesse dos filhos, sua emancipação como pessoa, na perspectiva de sua futura independência." (TEPEDINO, 2004, p. 41).

45 Acerca do tema, ensina Lôbo (2011, p. 75): "Em verdade ocorreu uma completa inversão de prioridades, nas relações entre pais e filhos, seja na convivência familiar, seja nos casos de situações de conflitos, como nas separações de casais. O pátrio poder existia em função do pai; já o poder familiar existe em função e no interesse do filho. Nas separações dos pais o interesse do filho era secundário ou irrelevante; hoje, qualquer decisão deve ser tomada considerando seu melhor interesse. O princípio parte da concepção de ser a criança e o adolescente como sujeitos de direitos, como pessoas em condição peculiar de desenvolvimento, e não como mero objeto de intervenção jurídica e social quando em situação irregular, como ocorria com a legislação anterior sobre os 'menores'. Nele se reconhece o valor intrínseco e prospectivo das futuras".

46 Trata-se elemento fundamental da constituição prospectiva do Direito Civil, de há muito perscrutada pela Teoria Crítica do Direito Civil, que assim enuncia desafio à comunidade jurídica especializada: "Descobrir o direito pela força criadora dos fatos [...], captando a legítima 'revolta dos fatos contra o código' sem a irresignação que daí retirava Gaston Morin, apreendendo que o caráter ôntico do direito está na sociedade e na realidade social, econômica e política" (FACHIN, 2009, p. 12).

47 A liberdade negativa se traduz como liberdade de coerção, como um espaço de não determinação em que o indivíduo pode eleger as alternativas para ação que melhor atenderem a seus desígnios. A propósito, esclarece von Mises: "Como um termo praxeológico, a liberdade se refere à esfera em que um agente pode escolher entre modos de ação alternativos. Um homem é livre contanto que possa escolher os fins e os meios a serem empregados para atingimento desses fins.". Tradução livre. No original: "As a praxeological term, freedom refers to the sphere within which a acting individual is in a position to choose between alternative modes of action. A man is free in so far as he is permitted to choose ends and the means to be used for the attainment of those ends." (von MISES, 1996, p. 279).

48 A liberdade positiva exprime uma liberdade para a tomada de decisões e, consequentemente, para o exercício de senhorio sobre os rumos da vida do agente, com um sentido de autorrealização. Execrada por Berlin, mas prestigiada pelos adeptos de abordagens liberal-igualitárias, como Crocker, a liberdade positiva é valorada desde os prismas individual e social, como a expressão da dita liberdade dos antigos. V., a propósito: HEYMAN, 1992; FARRELL, 1989; CROCKER, 1980, p. 10-47. 
A compreensão de que a função do instituto fundamental de Direito Civil família consiste na promoção de liberdades, com a conseguinte leitura do melhor interesse da criança nessa pauta, permite, sob o prisma da liberdade substancial, ${ }^{49}$ entendê-lo não simplesmente como bem-estar do menor (Kindeswohls, na dicção de Schwenzer), mas como um agregado de capacidades e funcionalidades. ${ }^{50}$ Assim, o adensamento do melhor interesse da criança em disputas de guarda, para efeito de fixação de lar de referência, por exemplo, pode se dar, coerentemente à promoção de sua liberdade substancial, pela via da apreciação da ambiência e da relação paternal que melhor provê conjuntos capacitatórios. No limite, os mais elementares, à moda explicitada por Nussbaum (2003, p. 40-50), em tentativa de precisão do argumento de Sen, resultou na enunciação de rol aberto de dez capacidades centrais ou elementares: (i) vida (ou condições propícias a uma vida digna de duração normal); (ii) saúde corporal, a incluir abrigo, alimentação e amparo médico adequados; (iii) integridade corporal, a compreender a não exposição à violência e autonomia para realização de escolhas quanto ao próprio corpo; (iv) sentidos, imaginação e pensamento, especialmente no sentido de ter autonomia para conformar e expressar informadas concepções de bem; ( $v$ ) emoções, a contemplar a formação de vínculos com outros seres e coisas, e a não sujeição ao medo e à ansiedade; (vi) razão prática, isto é, "ter condições de formar uma concepção de bem e pensar criticamente acerca de seu plano de vida" (NUSSBAUM, 2003, p. 41); (vii) afiliação, entendida como (a) oportunidade de viver com e em relação com outros, segundo uma espécie de ética da alteridade; e (b) ter as bases sociais do autorrespeito e da não humilhação, com prestígio da própria dignidade e da dignidade do outro, qualquer que seja sua origem, credo, raça, orientação sexual, etnia, etc.; (viii) contato com outras espécies; (ix) lazer e recreação; $\mathrm{e}(x)$ controle sobre o próprio ambiente. ${ }^{51}$

Esse rol de capacidades centrais ao desenvolvimento de funcionalidades da criança - sem o que não se pode falar, rigorosamente, em liberdade substancial e em promoção de seu melhor interesse - permite coser arrazoados, consistentes, controláveis e confiáveis, além de coerentes com a recompreensão dos fundamentos, sentidos e finalidades dos institutos fundamentais de Direito Civil (particularmente das famílias, dado o recorte ora promovido). Por esse caminho, e sem olvidar a inafastável exigência de embasamento em elementos de convicção produzidos pelas partes, a asserção do lar de referência em disputas relativas à guarda compartilhada, ou mesmo a excepcional atribuição de guarda unilateral a determinado genitor, pode escapar da discricionariedade e do obscurantismo inerente à invocação não criteriosa de enunciados normativos indeterminados. Há, pois, aqui, um viés de promoção de liberdade(s) e coerência do Direito.

\section{Conclusão}

Os institutos fundamentais de Direito Civil - particularmente a família - passaram, em virtude de viragens caras ao advento da jovem democracia constitucional brasileira, por uma profunda releitura de seus fundamentos, sentidos e finalidades. Especialmente quanto a essas últimas, afirma-se a de promoção de múltiplos perfis de liberdades humanas, à moda sustentada por Pianovski Ruzyk. Essa compreensão confere norte às discussões tangentes ao sentido das normativas fundamentais ao governo jurídico das relações entre particulares, sobretudo no que toca aos enunciados normativos deliberadamente indeterminados, como, na ambiência das famílias, o melhor interesse da criança.

49 Isto é: tomada não somente como a abertura estrutural do conjunto de leis e da economia para que cada indivíduo possa estabelecer suas escolhas, mas como o conjunto das possibilidades reais de escolha, no sentido dos condicionantes e limites que permitem estabelecer as preferências do sujeito (Cf. SEN, 1993, p. 522 e ss.)

50 "Funcionalidades representam partes do estado de uma pessoa - particularmente as várias coisas que ela consegue fazer ou ser na condução de sua vida. A capacidade de uma pessoa reflete a combinação alternativa de funcionalidades que a pessoa pode alcançar, e das quais ela pode escolher um conjunto. A abordagem é baseada numa visão da vida como uma combinação de diversos 'seres e fazeres', de modo que a qualidade de vida se define em termos da capacidade de alcançar funcionalidades valoradas [pelo sujeito]". Tradução livre. No original: "Functionings represent parts of the state of a person - in particular the various things that he or she manages to do in leading a life. The capability of a person reflects the alternative combinations of functionings the person can achieve, and from which he or she can choose one collection. The approach is based on a view of living as a combination of various 'doings and beings', with quality of life to be assessed in terms of the capability to achieve valuable functionings" (SEN, 1993, p. 31).

51 A lista se preserva em escritos mais recentes, cf. NUSSBAUM, 2011, p. 33-34. 
Aliás, por remeter a seres em desenvolvimento, cuja formação para o mundo contemporâneo integra responsabilidades atribuídas aos pais e à sociedade, o viés promotor de liberdade inerente à família e ao melhor interesse da criança se revela ainda mais pungente. A sua tônica recai - e nem poderia ser diferente - sobre o perfil substancial de liberdade. Vertido em termos do capabilities approach, de Sen e Nussbaum, traduz-se como um conjunto de componentes que permitem à pessoa formular e perseguir suas próprias concepções de bem. Isto é: como as condições necessárias à vivência de liberdade positiva nos espaços delimitados pelo viés negativo da liberdade. Assim, se as famílias se prestam à promoção da liberdade de seus integrantes, especialmente daqueles em formação, é certo que o atendimento ao melhor interesse da criança e do adolescente, para ser coerente com essa função, requer provimento de conjuntos capacitatórios elementares - os quais, em nome da objetividade, podem ser operativamente reduzidos ao rol das capacidades centrais enunciadas por Nussbaum.

Por esse viés, mostra-se possível coser razões coerentes e universalizáveis - nos sentidos aproximados aos que MacCormick confere a esses verbetes - a embasar decisões atinentes a casos concretos nos quais o melhor interesse da criança e do adolescente esteja em disputa (especialmente, como se trabalhou na dimensão do exemplo, em contendas sobre a guarda de filhos). Com isso, vislumbra-se caminho para o bom trato do melhor interesse da criança, tomado como exemplar de enunciado normativo deliberadamente indeterminado, o que acena à viabilidade da conciliação entre promoção de liberdades (mormente em concreto) e coerência na tomada de decisões jurídicas controláveis, calculáveis e confiáveis.

\section{Referências}

AARNIO, A. Derecho, racionalidad y comunicación social: ensayos sobre filosofia del derecho. Cidade do México: Fontamara, 2008.

ALBUQUERQUE, F. S. A família eudemonista do século XXI. In: PEREIRA, R. Cunha (coord.). Família entre o público e o privado. Belo Horizonte: IBDFAM, 2012. p. 88-95.

ALEXY, R. Teoría de la argumentación jurídica: la teoria del discurso racional como teoria de la fundamentación jurídica. Tradução: Manuel Atienza, Isabel Espejo. Madri: Centro de Estudios Constitucionales, 1997.

ALMADA, N. M. Direito de família. São Paulo: Brasiliense, 1987. v.1.

AMAYA, A. La coherencia en el derecho. DOXA: Cuadernos de Filosofia del Derecho, Alicante, n. 35, p. 59-90, 2012.

AMAYA, A. Legal justification by optimal coherence. Ratio juris, Nova Jersey, v. 24, n. 3, p. 304-329, set. 2009.

AMAYA, A. The tapestry of reason: an inquiry into the nature of coherence and its role in legal argument. Oxford: Hart Publishing, 2015.

ARNT RAMOS, A. L. Dogmática e efetividade: o papel da civilística no desbravamento de espaços de liberdades. Revista Brasileira de Direito Civil, Belo Horizonte, v. 11, n. 1, p. 17-35, jan./mar. 2017.

ARNT RAMOS, A. L. Ensaio de uma (auto)crítica: o direito civil contemporâneo entre a tábua axiológica constitucional e a constituição prospectiva. Pensar - Revista de Ciências Jurídicas, Fortaleza, v. 23, n. 4, p. 1-9, out./dez. 2018. Disponível em: https://periodicos.unifor.br/rpen/article/view/7599/pdf. Acesso em: 16 jan. 2020.

ATIENZA, M. As razões do direito: teoria da argumentação jurídica. 3. ed. Tradução: Maria Cristina Guimarães Cupertino. São Paulo: Landy, 2003.

ATIENZA, M.; MANERO, J. R. Ilícitos atípicos: sobre o abuso de direito, fraude à lei e desvio de poder. Tradução: Janaina Roland Matida. São Paulo: Marcial Pons, 2014.

BARBOZA, H. H. O princípio do melhor interesse da criança e do adolescente. In: CUNHA PEREIRA, R. (coord.). A família na travessia do milênio: anais do II Congresso Brasileiro de Direito de Família. Belo Horizonte: Del Rey, 2000. p. 201-214. 
BODIN DE MORAES, M. C. A nova família, de novo: estruturas e função das famílias contemporâneas. Pensar - Revista de Ciências Jurídicas, Fortaleza, v. 18, n. 2, p. 587-628, maio/ago. 2013.

BOTERO, A. Crítica da concepção de sistema jurídico e razão prática de Robert Alexy. In: BOTERO, A. Estudos de história e filosofia do direito. Tradução: Aberto K. Arbex et al. Curitiba: Juruá, 2013. p. 183-226.

CARBONERA, S. M. Aspectos históricos e socioantropológicos da família brasileira: passagem da família tradicional para a família instrumental e solidarista. In: MENEZES, J. B.; MATOS, A. C. H. (org.). Direito das famílias por juristas brasileiras. São Paulo: Saraiva, 2013. p. 33-66.

COHEN, J. E. What privacy is for. HLR, Cambridge, v. 126, n. 7, p. 1904-1933, 2013.

COSTA, P. Democracia política e Estado Constitucional. In: COSTA, P. Soberania, representação, democracia: ensaios sobre a história do pensamento jurídico. Tradução: Érica Hartmann. Curitiba: Juruá, 2010. p. 33-66.

CROCKER, L. Positive liberty: an essay in normative political philosophy. Boston: Martinus Nijhoff, 1980.

DWORKIN, D. Justice for hedgehogs. Cambridge: Harvard University Press, 2011.

DWORKIN, R. Law's empire. Cambridge: Harvard Belknap Press, 1986.

DWORKIN, R. The model of rules. Yale Faculty Scholarship Series, paper 3609, 1967. [online]. Disponivel em: http://digitalcommons.law.yale.edu/fss_papers/3609. Acesso em: 26 jun. 2019.

FACHIN, L. E. Questões do direito civil brasileiro contemporâneo. Rio de Janeiro: Renovar, 2009.

FACHIN, L. E. Direito Civil: sentidos, transformações e fim. Rio de Janeiro: Renovar, 2015.

FACHIN, L. E. Inovação e tradição no direito de família contemporâneo sob o novo código civil brasileiro. Ânima, Curitiba, v. 3, n.1, p. 1-32, 2010. Disponível em: http://www.anima-opet.com.br/pdf/anima3/ anima3-Luiz-Edson-Fachin.pdf. Acesso em: 26 jun. 2019.

FARRELL, M. D. Libertad negativa y libertad positiva. Revista del Centro de Estudios Constitucionales, v.1, n. 2, p. 9-20, jan./abr. 1989.

HART, H. L. A. Analytical jurisprudence in mid-twentieth century: a reply to Professor Bodenheimer. University of Pennsylvania Law Review, Filadélfia, v. 105, n.7, p. 953-975, 1957.

HART, H. L. A. The concept of law. Oxford: Claredon Press, 1975.

HEYMAN, S. J. Positive and negative liberty. Chicago-Kent Law Review, Chicago, v. 68, n. 1, p. 81-90, 1992.

HIRONAKA, G. M. F. N. A incessante travessia dos tempos e a renovação dos paradigmas: a família, seu status e seu enquadramento na pós-modernidade. In: BEZERRA DE MENEZES, J.; MATOS, A. C. H.

(org.). Direito das famílias por juristas brasileiras. São Paulo: Saraiva, 2013. p. 17-32.

LÔBO, P. L. N. Direito civil: famílias. 4. ed. São Paulo: Saraiva, 2011.

LÔBO, P. L. N. Entidades familiares constitucionalizadas: para além do numerus clausus. In: PEREIRA, R. C. (coord.). Família e cidadania: o novo CCB e a vacatio legis. Belo Horizonte: Del Rey, 2002. p. 89107.

MACCORMICK, N. Argumentação jurídica e teoria do direito. Tradução: Waldéa Barcellos. São Paulo: Martins Fontes, 2006.

MACCORMICK, N. Institutions of law: an essay in legal theory. Oxford: Oxford University Press, 2007.

MACCORMICK, N. Retórica e estado de direito: uma teoria da argumentação jurídica. Tradução:

Conrado Hübner Mendes, Marcos Paulo Veríssimo. São Paulo: Elsevier, 2008.

MARANHÃO, J. Positivismo jurídico lógico-inclusivo. São Paulo: Marcial Pons, 2012.

MARMOR, A. Legal Positivism: still descriptive and morally neutral. Oxford Journal of Legal Studies, Oxford, v. 26, n. 4, p. 683-704, 2006. 
MATOS, A. C. A família recomposta: em busca de seu pleno reconhecimento jurídico. In: BEZERRA DE MENEZES, J.; MATOS, A. C. H. (org.). Direito das famílias por juristas brasileiras. São Paulo: Saraiva, 2013. p. 319-336.

MICHELMAN, F. I. Constitutional authorship. In: ALEXANDER, L. Constitutionalism: philosophical foundations. Nova lorque: Cambridge University Press, 1998. p. 64-98.

NUSSBAUM, M. Capabilities as fundamental entitlements: Sen and social justice. Feminist Economics, Abingdon, v. 9, n. 2, p. 33-59, 2003.

NUSSBAUM, M. Creating capabilities: the human development approach. Cambridge: Harvard University Press, 2011.

NUSSBAUM, M. Social contracts and three unsolved problems of justice. In: NUSSBAUM, M. Frontiers of justice: disability, nationality, species membership. Cambridge: Harvard University Press, 2007. p. 9-95.

PIANOVSKI RUZYK, C. E. Famílias simultâneas: da unidade codificada à igualdade constitucional. Rio de Janeiro: Renovar, 2005.

PIANOVSKI RUZYK, C. E. Institutos fundamentais de direito civil e liberdade(s): repensando a dimensão funcional dos contratos, da propriedade e da família. Rio de Janeiro: GZ, 2011.

POKOL, B. The juristocratic State: its victory and possibility of taming. Budapeste: Dialóg Campus Kiadó, 2017.

POSCHER, R. The hand of Midas: when concepts turn legal, or deflating the Hart-Dworkin debate. In: HAGE, J.; PFORDTEN, D. (org.). Concepts in Law. Dodrecht: Springer, 2009. p. 99-116.

PUGLIESE, W. A ratio da jurisprudência: coerência, integridade, estabilidade e uniformidade. 2016. Tese (Doutorado em Direito) - Programa de Pós-graduação em Direito, Universidade Federal do Paraná, Curitiba, 2016.

REALE, M. O projeto de código civil: situação atual e seus problemas fundamentais. São Paulo: Saraiva, 1986.

REGLA, J. A. Positivismo y postpositivismo: dos paradigmas jurídicos en pocas palavras. DOXA: Cuadernos de Filosofia del Derecho, Alicante, n. 30, p. 655-675, 2007. Disponível em: https://doxa.ua.es/ issue/view/2007-n30. Acesso em: 16 jan. 2020.

ROSS, A. Sobre el derecho y la justicia. Tradução; Genario Carró. Buenos Aires: EUDEBA, 1963.

SCHMIDT, J. P. Zehn Jahre Art. 422 Código Civil: licht und schatten bei der anwendung des grundsatzes von treu und Glauben in der brasilianischen gerichtspraxis. DBJV Mitteilungen: Hannover, 2014. b. 2.

SCHWENZER, I. Familienrecht und gesellschaftliche Veränderungen: Gutachten zum Postulat 12.3607 Fehr "Zeitgemässes kohärentes Zivil- insbesondere Familienrecht". [online]. Disponível em: https://www.bj.admin.ch/dam/data/bj/publiservice/publikationen/berichte/familienrecht/gutachtenschwenzer-d.pdf. Acesso em: 26 jun. 2019.

SCHWENZER, I.; AESCHLIMANN, S. Zur Notwendigkeit einer Diziplin "Familienwissenschaft". In: DUBS, R., FRITSCH, B.; SCHAMBECK, H. (org.). Bildungswesen im umbruch. forderungen von politik, wirtschaft und gesellschaft: festschrift zum 75 geburtstag von Professor Dr. jur. et Dr. Phil. Hans Giger, Emeritus der Universität Zürich. Zurique: Neue Zürscher Zeitung, 2006. p. 501-511.

SEN, A. Capability and well-being. In: NUSSBAUM, M.; SEN, A. (org.). The quality of life. Oxford: Claredon Press, 1993. p. 31-60.

SEN, A. Markets and freedoms: achievements and limitations of the market mechanism in promoting individual freedoms. Oxford Economic Papers, Oxford, v. 45, n. 4, p. 519-539, 1993.

STRECK, L. $\mathbf{O}$ que é isto: decido conforme minha consciência? Porto Alegre: Livraria do Advogado, 2010. 
TEPEDINO, G. A disciplina jurídica da guarda e autoridade parental na ordem civilconstitucional. Revista Trimestral de Direito Civil, Rio de Janeiro, v. 17, ano 5, p. 33-49, jan./mar. 2004. TIMSIT, G. La codification, transcription ou transgression de la loi? Droits. Paris, v. 24, n. 1, p. 83-93, jan. 1996.

VELLUZZI, V. Le clausole generali: semântica e política del diritto. Milão: Giuffrè, 2010.

VON MISES, L. Human action: a treatise on economics. 4. ed. São Francisco: Fox \& Wilkes, 1996.

Recebido em: 16/01/2020

Aprovado em: 07/02/2020 